\title{
Coarctation of the aorta in Kabuki syndrome
}

\author{
H E Hughes, S J Davies
}

\begin{abstract}
The incidence of congenital heart defects in patients with Kabuki syndrome is estimated to be about $30 \%$. To date, no specific type of heart malformation is known to be associated with the syndrome. A further 20 unselected children with Kabuki syndrome are presented. The incidence of heart abnormalities in these children is almost twice that previously reported $(55 \%)$ and juxtaductal coarctation occurs with a frequency of $25 \%$.

(Arch Dis Child 1994; 70: 512-514)
\end{abstract}

Although Kabuki (make-up) syndrome* was first described in $1981^{12}$ and its incidence in Japan later estimated to be around $1 / 32000,{ }^{3}$ appreciation of the diagnosis in the West has been relatively recent, with the first large series in mostly Caucasian children published in 1992. ${ }^{4}$ The key diagnostic features include postnatal growth retardation, mild to moderate developmental delay, and a facies characterised by elongated palpebral fissures with eversion of the lateral margins of the lower lids. Ohdo et al ${ }^{5}$ were the first to draw attention to the association between the syndrome and congenital heart disease. Niikawa et al, in their 1988 series, ${ }^{3}$ found that a third of their patients had a heart defect and this finding was later confirmed by Philip et $a l,{ }^{4}$ who also stated that the syndrome appeared not to be associated with any specific type of heart abnormality.

We present here a further 20 unselected children with a definite diagnosis of Kabuki syndrome: six boys and 14 girls, ranging in age from 10 months to 13 years. All have had a normal chromosome study and two have had a normal 22q fluorescent in situ hybridisation study. Clinical details on all of these patients were reviewed and 11 were noted to have a heart defect (table). Five had an apparently isolated cardiac abnormality and one child had a pansystolic murmur on ausculation but no further clinical or echocardiographic detail is available. In the remaining five children (two boys, three girls) with more than one cardiac abnormality, operative details confirmed the preoperative echocardiographic diagnosis of aortic juxtaductal coarctation.

Institute of Medical Hospital of Wales, Heath Park, Cardifi CF4 4XW

H E Hughes

S J Davies

Correspondence to: Dr Hughes.

Accepted 8 February 1994
*The authors chose to use the term 'Kabuki syndrome' rather and upsetting to families. than 'Kabuki make-up', as the latter term often is unacceptable

\section{Case histories}

CASE 1

This child (fig A) presented in heart failure at 4.5 months and had an operation at 6 months. At operation, a muscular ventricular septal defect, a preductal coarctation, and a patent ductus arteriosus were confirmed. The aortic isthmus was approximately $1 \mathrm{~cm}$ in length and $4 \mathrm{~mm}$ in diameter, narrowing slightly at its terminal end where there was a tight shelf-like coarctation immediately proximal to the widely patent ductus arteriosus.

\section{CASE 2}

In this child (fig B) a cyanotic episode 11 hours after birth led to a cardiac evaluation and an operation at 2 days of age. It was then noted that the patent ductus, left sublavian artery, and the aortic arch all met at almost the same point, there being no real aortic isthmus - that is, a juxtaductal coarctation. There was also a patent ductus arteriosus and a perimembranous ventricular septal defect. A later postoperative echocardiogram confirmed the presence of a bicuspid aortic valve.

\section{CASE 3}

A routine prenatal ultrasound scan at 34 weeks' gestation suggested a cardiac anomaly consistent with a coarctation of the aorta. At operation (2 days of age), a large patent ductus arteriosus and a hypoplastic aortic arch were noted. On opening the aorta and aortic isthmus, it became apparent that the patent ductus arteriosus was a continuation of the ascending aorta and that a large amount of ductal tissue was almost occluding the aortic isthmus. There was also a bicuspid aortic valve (fig C).

Congenital heart disease in Kabuki syndrome. Twenty patients aged 10 months to 13 years

\begin{tabular}{ll}
\hline Isolated defect & $5(25 \%)$ \\
VSD & $3^{2}$ \\
Secundum ASD & 1 \\
Bicuspid AV & 1 \\
Juxtaductal coarctation & $5(25 \%)$ \\
Case 1: coarctation; VSD; PDA & 1 \\
Case 2: coarctation; VSD; bicuspid AV; PDA & 1 \\
Case 3: coarctation; bicuspid AV; PDA & 1 \\
Case 4: coarctation; ASD; PDA & 1 \\
Case 5: coarctation; VSD; bicuspid AV & 1 \\
Undelineated & $1(5 \%)$ \\
Normal echocardiogram & $4(20 \%)$ \\
Clinically normal (no echocardiogram) & $5(25 \%)$ \\
\hline ASD=atrial septal defect; VSD=ventricular septal defect; \\
PDA=patent ductus arteriosus; AV=aortic valve. \\
^In each case the juxtaductal coarctation was associated with a \\
hypoplastic aortic isthmus.
\end{tabular}





Cases 1-4 showing typical facial changes of Kabuki syndrome including elongated palperbal fissures, mild ptosis, and prominent ears. Case $1(A)$ shows the accentuated depression that is often seen below the midpoint of the lower lip.

\section{CASE 4}

This child (fig D) was investigated for heart failure at 3 weeks of age when she presented with failure to thrive, increasing tachypnoea, and sweaty episodes. An echocardiogram showed a moderate atrial septal defect, a small aortic arch and a shelf in the coarctation site which was distal to the left sublavian artery. At 6 weeks of age the patent ductus was ligated and the coarctation repaired.

\section{CASE 5}

This child was investigated at 8 weeks of age for signs suggestive of an aortic coarctation, which was later corrected by an operation. He was also noted to have a ventricular septal defect, an aberrant right subclavian artery, and a bicuspid aortic valve.

\section{Discussion}

Since the original description of Kabuki syndrome in 1981,12 recognition of the phenotype in the Western population has been relatively recent. The ease with which the 20 children in our series were ascertained over a short period of time, however, seems to confirm the Japanese experience that this is not an uncommon syndrome. As clinicians become more familiar with the phenotype and the syndrome's association with congenital heart disease is better appreciated, it is possible that Kabuki syndrome will equal other more well known dysmorphic cardiac syndromes, such as Williams and Noonan's syndromes, in the awareness of paediatricians and paediatric cardiologists.

In the previously reported large series of patients with Kabuki syndrome, the incidence of heart abnormalities was about $30 \%$ and no particular defect seemed to predominate. ${ }^{3} 4$ In the current study of 20 unselected children presenting in genetics clinics (nine in the United Kingdom and one in Canada), 11 $(55 \%)$ had a cardiac malformation. Five children $(25 \%)$ had more than one documented cardiac malformation which, in all cases, included an aortic coarctation. A detailed review of the cardiovascular features in these five children revealed a striking similarity between the structural changes. All presented in infancy (mostly within the first few weeks of life) with a hypoplastic aortic isthmus and a juxtaductal coarctation. Four of the five had a patent ductus arteriosus and, as commonly seen with this type of coarctation, at least three of the five children had an associated bicuspid aortic valve. The latter anomaly was also found in one other 
child in the isolated group but, unfortunately, there are no further details available on the aortic arch in this child.

Clark classified congenital cardiac malformations into four distinct types according to their presumed pathogenetic mechanisms, namely mesechymal tissue migration defects, and those resulting from abnormal cardiac haemodynamics, cellular death, and abnormalities of the extracellular matrix. ${ }^{6}$ The complex cardiac anomalies in the children with Kabuki syndrome in our series fit into the second of these groups, namely malformations related to altered cardiac haemodynamics or flow defects. Significantly, the defects differ from the conotruncal malformations seen in 22 del $\mathrm{q}(11)$, velo-cardio-facial/DiGeorge syndrome, which is also known to be associated with an abnormal aortic arch. ${ }^{7}$ Therefore it may not be surprising that the chromosome \#22 studies that have been undertaken on the children in this series (including patient 5) were negative.

The high incidence of cardiac flow defects, especially juxtaductal coarctation and its accompanying anomalies, in these children is intriguing. The known association of coarctation and bicuspid aortic valve in Turner's syndrome ${ }^{8}$ makes the observation of a possible link between Kabuki syndrome and $\mathrm{XrX} / \mathrm{XrY}$ syndromes ${ }^{3} 910$ even more relevant to the search for its chromosomal localisation. Kabuki syndrome has all the hallmarks of a microdeletion syndrome and even in 1988 Niikawa et al suggested that the genes located in the pseudoautosomal regions of the $\mathrm{X}$ and $\mathrm{Y}$ chromosomes should be considered as candidate genes. ${ }^{3}$

This series of 20 children highlights the association between Kabuki syndrome and a specific type of cardiac anomaly, namely juxtaductal coarctation. Therefore this syndrome should be considered in the differential diagnosis of any infant presenting with aortic coarctation, postnatal growth retardation, developmental delay, and facial dysmorphism. Conversely, any child with Kabuki syndrome, despite a normal clinical cardiac evaluation, should have an echocardiographic assessment paying particular attention to the aortic arch.

The authors thank their colleagues for contributing patients to the series and for providing clinical details. They include Drs D Donnai, A Fryer, C Garrett, S Holder, J Hurst, S Huson, P Jardine, W Meschino, D Pilz, S Slaney, and K Temple. We P Jardine, W Meschino, D Pilz, S Slaney, and K Temple. We also thank Dr G Stuart for his help
descriptions of the cardiac findings.

1 Niikawa N, Matsuura N, Fukushima Y, et al. Kabuki make-up syndrome: a syndrome of mental retardation, unusual facies, large and protruding ears, and postnatal growth deficiency. F Pediatr 1981; 99: 565-9.

2 Kuroki Y, Suzuki Y, Chyo H, et al. A new malformation syndrome of long palpebral fissures, large ears, depressed nasal tip, and skeletal anomalies associated with postnatal dwarfism and mental retardation. 7 Pediatr 1981; 99: 570-3.

3 Niikawa N, Kuroki Y, Kajii T, et al. Kabuki make-up Niikawa-Kuroki) syndrome: a study of 62 patients. Am 7 Med Genet 1988; 31: 565-89.

4 Philip N, Meinecke P, David A, et al. Kabuki make-up (Niikawa-Kuroki) syndrome: a study of 16 non-Japanese cases. Clinical Dysmorphology 1992; 1: 63-77.

5 Ohdo S, Madokoro H, Sonoda T, et al. Kabuki make-up syndrome (Niikawa-Kuroki syndrome) associated with congenital heart disease. 7 Med Genet 1985; 22: 126-7.

6 Clark EB. Mechanisms in the pathogenesis of congenital cardiac malformations. In: Pierpoint MEM, Moller JH, eds. Genetics of cardiovascular disease. New York: KluwerNijhoff (US), 1987: 3-11.

7 Scambler PJ, Kelly D, Lindsay E, et al. Velo-cardio-facial syndrome associated with chromosome 22 deletions encompassing the DiGeorge locus. Lancet 1992; 339: 1138-9.

8 Miller MJ, Mitchell EG, Lippe BM, et al. Echocardiography reveals a high incidence of bicuspid aortic valve in Turner syndrome. $\mathcal{f}$ Pediatr 1983; 102: $47-50$

9 Kajii T, Tsukahara M, Murano I, Matsuura S. Kabuki make-up-Ullrich-Turner syndrome: report of 12 patients. European Society of Human Genetics. Elsinore, Denmark, 1992: 93

10 Dennis NR, Collins AL, Crolla JA, et al. Three patients with ring (X) chromosomes and a severe phenotype. f Med Genet 1993; 30: 482-6. 